\title{
NORMATIVITY IS THE KEY TO THE DIFFERENCE BetWeEn The HuMAN AND THE NATURAL SCIENCES
}

\author{
Wolfgang Spohn
}

In this paper I take the human sciences to comprise psychology, social, economic, and political sciences, archaeology, history, ethnology, linguistics, philologies, literary and cultural studies, and similar fields having emerged besides and in between. So, the human sciences study the individual and collective ways and products of the human mind. After the term "Geisteswissenschaften" has narrowed its meaning, the term "Humanwissenschaften", "human sciences", seems more appropriate. By contrast, the natural sciences are to comprise all the other fields of empirical study, physics, astronomy, chemistry, biology, geology, engineering, etc. In this paper I would like to give an update of, and a fresh attempt at, the long-standing heated issue whether or not there is a principled difference between the human and the natural sciences.

\section{Where the Difference Between the Human and the Natural Sciences is Not}

The issue I am going to discuss starts long before the emergence of the special sciences, namely with Descartes' powerful introduction of a dualistic world picture, with his distinction of a res extensa being the object of the physical sciences and a res cogitans being the object of studies of the mind. We still see the repercussions of this dualism everywhere. However, philosophers found this ontological division always hard to accept, not to the least because of the great difficulties in accounting for the obvious causal relations between the physical and the mental; those causal relations seemed to call for a more unified picture. Today the old ontological dualism may well count as obsolete.

Still, there are remnants of the old dualism in the current philosophical debate about consciousness. We might explain human sciences as dealing with the emanations of human consciousness. Hence, those sciences would find their core in the present consciousness studies. However, dualism is no option there. Looking 
at phenomenal consciousness, the most evident form of consciousness, we find either the attempt at functionally explaining qualia or phenomenal contents, thus integrating them into the universal causal nexus. Or, if this should fail, as many believe including me, the only alternative seems to be to try to understand phenomenal consciousness directly as a biological phenomenon. Any kind of substance dualism would render further scientific inquiry of consciousness impossible. From this side, hence, we do not receive any confirmation for a principled division among the empirical research fields.

Let us look, hence, a bit more broadly at the history of our topic. When the issue came up after the emergence of the special sciences in the 18th and 19th century, the suspicion rather was that there is a principled methodological difference between the natural and the human sciences. This suggestion was forcefully introduced by Windelband (1884). He located a principled difference between the nomothetic and the ideographic disciplines, as he called them. The physical sciences proceed nomothetically; they attempt to subsume their phenomena under general laws and to thereby explain them, as physics paradigmatically does. By contrast, human studies proceed ideographically; they carefully inquire and describe singular constellations, individual small- or large-scale events, unrepeatable processes, as history paradigmatically does.

Certainly, empirical researchers proceed both ways. However, already the logical empiricists raised the objection that this distinction does not provide a suitable dividing line between the natural and the human sciences. Single events are scrutinized everywhere, in astronomy and geology, etc., just as well as in historical or economic studies, and the attempt to generalize is undertaken everywhere; certainly, there are economic laws and perhaps even laws of history. One may suggest that the types of laws involved are different. Indeed, there is a large current debate about so-called ceteris paribus laws (cf., e.g., Schrenk 2007). It is only fundamental science that states truly general, unconditioned laws, whereas all the special sciences at most come up with laws hedged by ceteris paribus clauses. However, even this view is contested; perhaps, ceteris paribus conditions run deeper. And it at best discriminates between fundamental and special and not between natural and human sciences.

This early debate about the lawful character of various disciplines was, however, only a prelude to a much more serious and encompassing debate initiated by Dilthey (1883) and the hermeneutic philosophy; this had a more pervasive impact. 
The idea was that the human sciences aim at understanding reached by a special, i.e., the hermeneutic method solving special epistemological problems or hermeneutic circles. These problems and this method were supposed to be quite unlike anything we find in the natural sciences.

There is no point in starting detailed argument now; However, I confess that the central claim of the hermeneutics always appeared implausible to me. Certainly, deciphering and interpreting an ancient text is very different an activity from, say, observing cells under the microscope. Where, however, is the principled methodological difference? From an ordinary language point of view, opposing understanding to explanation is an unhappy move, since that opposition simply does not exist. In the relevant contexts, the two terms are often exchangeable. The sciences strive to understand nature just as human studies strive to understand men; cells are objects no less to be understood than texts.

Of course, this remark is not quite fair; understanding was intended to have a narrower meaning when opposed to explanation. The focus of hermeneutic philosophy certainly was on linguistic understanding, on coming to terms with language, the unique and overwhelmingly powerful human faculty. Now, understanding old or foreign texts quite detached from context certainly is one of the most difficult linguistic tasks we actually face. Still, the fundamental hermeneutic problem was raised, I find, rather in analytic philosophy of language, in terms of radical translation, and Quine's (1960) lessons on the inscrutability of reference and the indeterminacy of translation and Davidson's (1984) attempt at breaking the basic hermeneutic circle of belief and meaning by his principle of charity were the philosophically more radical approaches. One may find Quine's strictly behavioristic approach to (stimulus) meaning too narrow and Davidson's behavioral base for inferring meanings too sparse. Still, there is no hint in their work that inquiring meanings, as far as it is possible, follows a fundamentally different methodology. The point is still clearer in Grice's (1957) promising program of naturalizing semantics. This program specified precise ways of inferring semantics from psychology and psychology from behavior, and no step of inference showed special features principally different from those made in other empirical fields. Hence, language and linguistic understanding did not seem to be the realms providing a distinction of the human sciences.

As a consequence, the issue was thrown back at the basic level where it belongs, i.e., to the question how to conceive of human action. There is no more 
basic level at which a principled difference between natural and human sciences could emerge; and reversely, if the difference cannot be perceived already there, the case is very likely to be hopeless. However, this is the level at which methodological dualists suffered their most dramatic defeat. Ryle (1949) originally suggested that dispositional explanation differs from causal explanation and that this difference is crucial for understanding human actions. Hempel (1961/62) and Davidson (1963) took the opposite view that dispositional explanation is a variety of causal explanation and that human actions have causes just like any other events. One may safely say, I think, that the causalists clearly won the upper hand; their view seems nowadays generally accepted. Von Wright (1971), who was about the strongest opponent to the causalists at that time just sounds strange when reread with present eyes. This outcome of the debate about the explanation of human actions always appeared to me to be the strongest point in favor of the unity of science and against the methodological disunity of the natural and human sciences.

This is how I would have presented the issue 10 years ago, and even today it is, I think, a fair, though partial description of the present state of discussion. However, I have changed my mind some years ago or, rather, I have realized that this change is entailed by my considerations in Spohn $(1993,2007)$. There is a principled methodological difference between the natural and human sciences. The basic point is that human sciences are shot through with normative considerations in an irreducible way in which natural sciences are not. I would like to explain this point in the rest of my paper.

\section{Normativity in an External and an Internal Perspective}

Normativity comes in many linguistic forms; the basic form, though, uses the auxiliaries "shall" or "should". A normative question asks, and a normative claim says, what I, or we, should do, or what should be the case. Usually, the realm of normativity is decomposed into two parts, which are, of course, interrelated. One part relates to our actions: What should we do? The other part relates to our beliefs: What should we believe? Thus the realm of the normative basically divides into theoretical and practical issues.

Now, it is essential to distinguish two perspectives on normative issues, a distinction I learnt from Hart (1961, pp. 54ff.). There is an external third-person per- 
spective, and there is an internal first-person perspective. In the external perspective we observe and state which norms a person has adopted and which norms actually hold in a given group or community. A rule is more than a regularity, a norm is not just normality. The surplus may be analyzed in various ways. A norm may be said to be enforced by sanctions either explicitly imposed by appropriate institutions or implicitly exerted within the community. Or a rule may be a convention in the sense of Lewis (1969), a behavioral regularity supported by an appropriate pattern of desires and mutual beliefs. Whatever the adequate analysis, it is clear that within the external perspective normative facts are nothing but empirical facts; it is simply a matter of empirical inquiry to find out about the norms actually governing a community.

Things look different, however, from the internal perspective. The difference shows up already in the peculiar ambiguity in calling a norm valid. This may mean that the norm is empirically valid, that it holds in, or is accepted by, a given community. Or it may mean that it is normatively valid, that it is to be accepted. The latter claim cannot be empirically confirmed or disconfirmed; it is subject to normative discourse where it may get approved or disapproved. Normative discourse is an essential part of the first-person perspective, a perspective we humans have and cannot escape. Whatever we do, it is legitimate to ask whether we should do, or have done, it; we have to take a normative stance, and taking no stance is, in a way, taking a stance as well.

Let me slightly expand on the pervasiveness of normative discourse. There are many norms of theoretical rationality. We have a lively normative dispute about good and bad inductive inferences, about the inference to the best explanation, the principle of minimizing cross-entropy, and more. The foundations of statistics can still not count as settled. Deterministic and probabilistic sciences seem to fall apart methodologically. And we do not only have arguments about general epistemological principles; we certainly have them in every specialized empirical field.

Then, of course, we have principles of practical rationality. The principle of maximizing conditional expected utility is perhaps the most basic and general one, but it is open to interpretation, counterexamples, and amendments. Game theory, no doubt, is a normative theory, too, though with some counterintuitive recommendations. There are quite a number of alternatives to standard decision theory, and there is a larger number of paradoxes which point to defects in our received 
picture of practical rationality. Again, we find a most lively and ramified normative dispute over those general principles. And in everyday life we continuously discuss about what is reasonable in various situations.

More salient than all such norms of rationality are the more substantial ethical norms about how to lead a good and virtuous life and moral norms of justice, fairness, and peaceful coexistence, norms that may enter legal codes or may be used as critical instances against positive law. There is no need to further emphasize the importance of moral discourse. It is a long-standing philosophical issue whether moral principles reduce to rationality principles. However, we need not take a stance. Even if there are two kinds of principles, they are both normative.

Is there normative truth? I may be silent on this issue. If it exists, it is not of the correspondence kind. It would be rather like pragmatic truth. Just as pragmatic truth is vaguely explained as that which is maintainable in the limit of empirical inquiry, normative truth might be conceived as being accepted in the limit of normative inquiry. However, we need not presuppose that all normative issues are settled in the limit; maybe, many of them are undecidable. What is important is that normative discourse is not merely a matter of confessions, it is governed by (often defeasible) reasons, and it is fallible and open-ended; firm convictions are fine, but dogmatism is not. In all those respects, normative discourse is very similar to empirical discourse, and it would be worthwhile to more thoroughly inquire the rules and patterns of normative argument. Still, empirical and normative arguments are different, simply because of their conclusions. This difference is obvious, even for those like me who do not think that each (defeasible) inference from is to ought has to be a fallacy (cf. Schurz 1997)

So, to resume, from the external perspective, the normative is just a kind of empirical phenomenon to be studied like other empirical phenomena. From our internal perspective, by contrast, the normative is entirely different from the empirical, even though connected. Keeping strictly to the external perspective, we could never grasp what all this normative business within the internal perspective is about.

\section{Human and the Natural Sciences Differ in Normative Involvement}

Now, what has all this to do with the alleged principled difference among the scientific disciplines? This is not obvious. The point is not simply that some disci- 
plines deal with normative issues and others do not. This is much too unspecific a statement. In fact, it is clear that all scientific disciplines deal with normative issues. Each researcher and each science manager must ask herself which fields to inquire and how to allocate resources. If we compare the amount of money invested into conquering cancer and that invested into healing malaria, is that fair? Practical normative questions abound in all disciplines.

Even if we declare such questions to be somehow external to science - they are not scientific questions to be answered by scientific methods -, enough normativity remains. Each inquiry is confronted with methodological issues that are theoretical normative issues. How do we best go about to conduct a given inquiry? Which experiment is most discriminative, which poll is most revealing? What should we infer from the data? Which hypothesis is the most plausible or the most explanatory? And so on. All these are normative, i.e., methodological issues, and we find them in all scientific disciplines. Most of them are answered as a matter course, though some more caution would well befit the scientists. In any case, these observations rather speak against any principled difference among the scientific disciplines.

Indeed, all disciplines are infected by so much normativity. The point is that only the human sciences are entangled with normativity in a special and much more far-reaching way, namely simply because only the human sciences deal with objects, namely us humans, that have an internal normative perspective. This point is familiar and not novel at all. I only want to grasp it as sharply as I can. So, let me elaborate:

It is, I said, that the human sciences empirically deal with all normative phenomena whatsoever and not only those concerning themselves, since they empirically deal with humankind that is occupied with all normative issues whatsoever. The crucial question now is: Can the human sciences do so by restricting themselves to the external perspective, from which normative phenomena are, as stated, a variety of empirical phenomena and may be studied accordingly? The crucial answer is: No, they cannot. Merely in order to do their empirical work properly they have to actively engage into normative theorizing from the internal perspective (or to listen to those thus actively engaged). That is, they have to do something no natural science has to do; they have to leave their empirical home and enter foreign terrain, i.e., normative discourse, in order to properly cultivate their home domain. 
Why should they have to do this? The basic reason is that there is a fundamental asymmetry in the explanation of human activities. Unless indeterminate, norms tell us what is right and wrong, correct and incorrect. We humans are receptive for normative considerations; this is what it means to have an internal normative perspective. This perspective is no idle play; it guides us. So, when I ask why Mary did something, the answer "because it was right" gives a first explanatory sketch in a way in which the alternative answer "because it was wrong" would not. If Mary has done something wrong, explaining this requires some additional explanation for deviating from the norm, whereas if Mary has done something right, it suffices, for a first step, to point to its compliance with the norm. Of course, in both cases we may richly detail the explanation; there remains a lot to be cleared up (though not necessarily by philosophers). However, the asymmetry just stated stays; there is always one thing more to explain in the case of wrong doings than in the case of right doings.

Or to express the same point in a different way: normative theorizing has a peculiar double role. On the one hand, it is just that, something emerging in normative discourse within the internal perspective. On the other hand, normative theorizing also serves as an empirical theory, precisely because of the human receptivity for norms. Of course, it does not deliver an empirically fully adequate theory; usually, we do more or other things than perfectly implementing norms. Still, it serves at least as an idealized empirical theory. Ideally, we would implement the norms, though actually we are imperfect. And as with any idealized theory, we need additional error theories correcting the idealized theory and making it empirically more adequate, thus explaining also deviations from the ideal. This is why we have the asymmetric explanatory situation mentioned above.

One may object that for arriving at this idealized theory it suffices to take the perspective of the external observer. From that perspective one can hypothesize the norms actually holding in the community under study. It is clear, then, that those hypothesized norms are not iron rules and hence need again to be supplemented by error theories. So, the objection goes, the principled point I was just trying to make is fully respected purely within the external perspective. At best, the objector may grant, it is much more difficult to hypothesize the actually valid norms from outside than with a familiarity of the internal normative discourse. However, ease and difficulty certainly are a matter of degree, not of principle. 
The objection misses, I think, the full force of the internal normative perspective. The idealized theory applied and amended in empirical research should not merely collect what the community presently thinks is right; it should state what is right, something that can be inquired only from within the internal perspective, even though only the limit of normative inquiry is definitive. Why should our empirical research appeal to an idealized theory in this strong sense? Because otherwise we cannot understand or explain the dynamics of our normative conceptions. To some extent the norms adopted by a community are a matter of fashion, and then one may speculate about the dynamics of fashions. To some extent, they are matter of historic contingency; there are only historic explanations why some countries drive on the right and not on the left or have a proportional instead of a majority voting system. To some extent, though, the dynamics of our normative conceptions can only be understood through our efforts to find out and do what is right. The movement of enlightenment and the evolution of science can only be understood as also being a fight for epistemic rationality, whatever its ultimate standards. The changing forms of society can only be understood as also being a fight for the right conceptions of freedom and justice. History is essentially driven by the evolution of human rights that can only be understood as a fight for finding and enforcing the right moral standards. Of course, these grand historic examples are reflected on each local and individual level.

Thus, referring only to the current normative conceptions observable from the external perspective yields too weak an idealized theory; we have to invoke the full normative theory as an ideal in order to represent the actual dynamics of normative conceptions as a history of errors and of approximations to the ideal. And this representation is available only from the internal and not from the external perspective. In a nutshell, since we have to apply the model of an ideal theory and supplementing error theories also in a dynamic perspective, the ideal theory to be used cannot refer to any momentary state, but must take an ideal stance towards the entire evolution that can only consist in the endpoint of this evolution. Of course, the endpoint is only a normative fiction that is actually never reached; humankind will be extinct before. At each moment we can only hypothesize what the endpoint will be. However, we can only hypothesize it from the forwardlooking normative point of view and never from the external point of view running behind. 
This is my argument why the human sciences, and only the human sciences, have to engage into normative theorizing from the internal perspective, something ordinarily not conceived as a scientific enterprise. However, if I am right, they have to do this even in respect of their empirical interests only. This is what fundamentally distinguishes them from the natural sciences.

Is this point able to account for the earlier views on the distinction between the human and the natural sciences? Certainly not for the nomothetic/ideographic distinction; but we dismissed that, anyway. Certainly, as far as the explanation of human actions is concerned. The point there is not an obscure opposition of ex-

planation and understanding. It is rather that the explanation of actions appeals to standards of practical rationality and even morality that can be acquired only in normative discourse. Only insofar, the explanation of actions is indeed different.

What about language and linguistic understanding? I am not sure. It has been strongly suggested in the recent years that linguistic meaning is thoroughly normatively infected; for instance, the basic tenet of Brandom (1994) is, roughly, that meaning is constituted in the communal practice of giving and accepting reasons. Indeed, according to any kind of inferential role semantics there is at least a close relation between the space of meaning and the space of reasons. And, of course, the space of reasons opens all dimensions of theoretical rationality and epistemic normativity. Such approaches to semantics are highly suggestive; that's why I am sympathetic to them. But they are constructively poor; that's why I am not sure about the relation between my argument and the argument from language.

\section{Is Methodological Dualism Compatible with Ontological Monism?}

At the beginning of my paper I dismissed a distinction of human and natural sciences on ontological grounds. However, if monism is our ontological option, does it not refute my argument for a principled difference? I think not. Let me conclude my paper with explaining why.

We may well grant the supervenience of the mental on the physical. This includes the supervenience of all our actual normative conceptions on the physical; if we had different ones, there has to be some physical difference, too. If there should be normative facts, those determined in the limit of normative inquiry, one may even grant that they supervene on the physical as well. However, they do so 
trivially, because, like mathematical truths, they do not depend at all on the physical.

The point now is that such ontological acknowledgments do not determine our epistemological third-person perspective. They do not speak for the primacy of the empirical over the normative point of view or for the irrelevance of the latter for the former. Why?

It is a well-known philosophical maneuver to turn ontological considerations into epistemological ones with the help of Laplace's demon. By knowing the ultimate ontological inventory of our world, the distribution of matter (at a given time) and the fundamental physical laws governing it, the demon can apparently know everything that is, and he can apparently explain every past and predict every future action and even every normative conception we tend to have. He seems to be the incarnation of our epistemologically perfected external perspective, and there is no place for the normative perspective in that perfection.

However, this is a seriously deceptive picture. We need to understand how wildly nonhuman the demon is. The point is not that in our indeterministic universe even the demon would not get far. Ontologically, we may grant strict determinism for the sake of the argument. The point is rather that neither we nor the demon are capable of specifying the supervenience relation that is only claimed to exist in our ontological professions, and that this incapability has very different, though converging reasons for us and the demon.

For us, the problem is not so much complete knowledge of fundamental physical laws; perhaps we are on the verge of it. For us, it is rather the demon's complete knowledge of particular physical facts (at a given time) and his perfect computational capacities. Both are entirely fictitious for us. It is safe to predict that we shall never exactly compute complex molecules in quantum mechanical terms and that, despite the bold declarations of neuroscientists, we can never have more than the roughest understanding of the physiological supervenience base of complex mental processes.

In particular, we have to proceed from the causalists' rudimentary explanation of our actions, which refers to principles of practical rationality and which is the only one consistent with our having a normative perspective; and we may and should specify, qualify, and amend this sketch in multifarious ways. As emphasized, we also evolve our normative point of view; we seek ever better and more complete answers to our normative questions. And as explained, we thereby pro- 
mote our empirical perspective; our normative conception serves as well as our empirical ideal. Any empirical theory that simply neglects our normative point of view is bound to be incomplete and inadequate.

The demon has the complementary problem. Well, not necessarily, the demon might also be an eliminativist and thus not care about supervenience. However, I take the eliminativist's prediction that our intentional idiom will eventually dissolve to be simply incredible. If so, it will not do for the demon to know everything there is to know on the basic ontological level of physics. He is still entirely ignorant of all relevant supervenience relations. If he wants to know what water is, he must first know our notion of water; then, of course, it is easy for him to establish that water is $\mathrm{H}_{2} \mathrm{O}$. If he is to predict whether or not I am happy tomorrow he must also know how happiness supervenes on all the physics he knows; and in order to know this he would first have to acquire the complex notion of happiness. Likewise for all the other mental concepts we have. In particular, he would need to have and exercise a normative perspective by himself; otherwise, he could never grasp what our normative discourse is all about.

From both sides, we thus arrive at the same conclusion. The demon needs to have a normative perspective, even if his sole aim is to complete his empirical picture. We have the normative perspective and have to respect it as an empirical ideal in doing empirical human studies. Hence, even from the empirical thirdperson perspective one is committed to the normative first-person perspective. One cannot do well in the former without engaging in the latter; you cannot complete empirical psychology and thus the other human sciences without engaging in normative considerations - something not required in the natural sciences. So, ontological unity in terms of suitable supervenience relations does not prevent there to be a principled methodological difference.

\section{Bibliography}

Brandom, Robert (1994), Making It Explicit, Cambridge, Mass.: Harvard University Press.

Davidson, Donald (1963), “Actions, Reasons, and Causes”, Journal of Philosophy 60, 685-700.

Davidson, Donald (1984), Inquiries into Truth and Interpretation, Oxford: Clarendon Press.

Dilthey, Wilhelm (1883), Einleitung in die Geisteswissenschaften, Leipzig.

Grice, H. Paul (1957), “Meaning”, Philosophical Review 66, 377-388.

Hart, Herbert L.A. (1961), The Concept of Law, Oxford: Oxford University Press. 
Hempel, Carl Gustav (1961/62), "Rational Action", Proceedings and Addresses of the APA 35, 523 ,

Lewis, David (1969), Convention: A Philosophical Study, Cambridge, Mass.: Harvard University Press.

Quine, Willard V.O. (1960), Word and Object, Cambridge, Mass.: MIT Press.

Ryle, Gilbert (1949), The Concept of Mind, London: Hutchinson.

Schrenk, Markus (2007), The Metaphysics of Ceteris Paribus Laws, Frankfurt a.M.: Ontos.

Schurz, Gerhard (1997), The Is-Ought Problem. A Study in Philosophical Logic, Dordrecht: Kluwer.

Spohn, Wolfgang (1993), "Wie kann die Theorie der Rationalität normativ und empirisch zugleich sein?”, in: L. Eckensberger, U. Gähde (eds.), Ethik und Empirie. Zum Zusammenspiel von begrifflicher Analyse und erfahrungswissenschaftlicher Forschung in der Ethik, Frankfurt a.M.: Suhrkamp, pp. 151-196.

Spohn, Wolfgang (2007), "The Core of Free Will", in: P. K. Machamer, G. Wolters (eds.), Thinking About Causes. From Greek Philosophy to Modern Physics, Pittsburgh: Pittsburgh University Press, pp. 297-309.

von Wright, Georg Henrik (1971), Explanation and Understanding, Ithaca: Cornell University Press.

Windelband, Wilhelm (1884), Aufsätze und Reden zur Einführung in die Philosophie, Freiburg. 